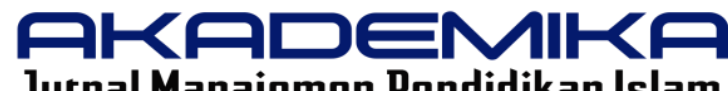

Jurnal Manajemen Pendidikan Islam

INSTITUT AGAMA ISLAM SUNAN KALIJOGO MALANG

P-ISSN 2622-9293 / E-ISSN 2721-9658

Volume 3 Nomor 1 Juni 2021

\title{
STUDI PENGGUNAAN MODEL PEMBELAJARAN PROBLEM BASED LEARNING DAN MODEL PEMBELAJARAN DIRECT INSTRUCTION KELAS X TKJ SMK NEGERI 1 BOYOLANGU
}

\author{
Ahmad Mubarok 1), Batriyana Ayu Puspitasari1) \\ 1)Institut Agama Islam Sunan Kalijaga Malang \\ 1)amubama45@gmail.com, batriyana@gmail.com
}

\begin{abstract}
Abstrak: Model pembelajaran yang sesuai dengan tujuan pembelajaran, materi yang diajarkan, dan karakteristik siswa, membuat proses belajar mengajar tercapai dengan optimal. Penelitian ini menggunakan pendekatan diskriptif kualitatif dengan jenis penelitian penelitian lapangan (Field Research). Data yang dipaparkan merupakan data tentang model pembelajaran yang masing-masing informan gunakan. Penelitian dilaksanakan di SMK Negeri 1 Boyolangu Kabupaten Tulungagung dengan notaben sekolah dengan prestasi tinggi terutama dijurusan Teknik Komputer dan Jaringan. Hasil penelitian dapat digunakan sebagai rujukan untuk meningkatan kualitas Standar Kompetensi Lulusan pada satuan pendidikan menengah kejuruan lainnya. Berdasarkan hasil analisis data hasil penelitian menunjukan bahwa 4 (empat) informan menggunakan model pembelajaran Problem Based Learning (PBL) dan 1 (satu) informan menggunakan model pembelajaran Direct Instruction (DI). Sehingga model pembelajaran yang paling tinggi tingkat penggunaanya adalah yang adalah model pembelajaran Problem Based Learning (PBL) dengan empat dari lima informan menggunakan model pembelajaran tersebut.
\end{abstract}

Kata Kunci: Model Pembelajaran Problem Based Learning, Model Pembelajaran Direct Instruction, Teknik Komputer dan Jaringan

\begin{abstract}
The learning model that is in accordance with the learning objectives, the material being taught, and the characteristics of the students, makes the teaching and learning process optimally achieved. This study uses a qualitative descriptive approach with the type of field research research (Field Research). The data presented is data about the learning model that each informant uses. The research was carried out at SMK Negeri 1 Boyolangu, Tulungagung Regency, with high achievement schools, especially in the Computer and Network Engineering major. The results of the study can be used as a reference to improve the quality of Graduate Competency Standards in other vocational secondary education units. Based on the results of data analysis, the results of the study showed that 4 (four) informants used the Problem Based Learning (PBL) learning model and 1 (one) informant used the Direct Instruction (DI) learning model. So that the learning model with the highest level of use is the Problem Based Learning (PBL) learning model with four of the five informants using the learning model.
\end{abstract}

Keywords: Problem Based Learning Model, Direct Instruction Learning Model, Computer and Network Engineering 


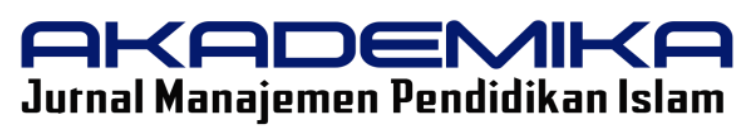

INSTITUT AGAMA ISLAM SUNAN KALIJOGO MALANG

P-ISSN 2622-9293 / E-ISSN 2721-9658

Volume 3 Nomor 1 Juni 2021

\section{LATAR BELAKANG}

Pendidikan kejuruan bertujuan untuk menghasilkan manusia yang produktif, yakni manusia kerja, bukan manusia beban bagi keluarga, masyarakat dan bangsanya. Sekolah Menengah Kejuruan (SMK) merupakan sekolah yang mampu menghasilkan Sumber Daya Manusia yang terampil dan berkualitas (Sinaga, 2013:79). Salah satu mata pelajaran keahlian yang diharapkan mampu menjadi interpretasi nyata dari Peraturan Pemerintah Republik Indonesia Nomor 19 Tahun 2005 tentang Standar Pendidikan Nasional adalah mata pelajaran keahlian Teknik Komputer dan Jaringan (TKJ).

Sekolah Menengah Kejuruan secara umum harus memiliki kecakapan: (1) pengetahuan dan ketrampilan khusus untuk jabatannya, (2) pengetahuan dan ketrampilan sosial, (3) emosional dan fisik dalam kehidupan sosial, (4) pengetahuan dan ketrampilan khusus dasar, dan (5) kejuruan umum, sosial serta pengetahuan dan ketrampilan akademik untuk jabatan, individu dan masa depannya (Muslim dalam Agustianto, 2014:2). Untuk memuhi kriteria kelulusan kejuruan, guru harus menguasai bahan yang diajarkan, terampil mengajarkannya, dan mampu menguasai berbagai kendala yang ditemui dalam pembelajaran (Toha, 2014:3). Guru harus mampu memilih dan menggunakan model pembelajaran dengan tepat. Model pembelajaran yang sesuai dengan tujuan pembelajaran, materi yang diajarkan, dan karakteristik siswa, membuat proses belajar mengajar tercapai dengan optimal.

Model pembelajaran merupakan pedoman bagi guru dan perancang pembelajaran dalam mengoptimalkan proses pembelajaran untuk mencapai tujuan pembelajaran (Trianto, 2011:51). Berdasarkan penelitian-penelitian tentang penerapan model pembelajaran di SMK yang telah dilakukan sebelumnya, terdapat beberapa model pembelajaran yang menunjukan pengaruh lebih tinggi terhadap hasil belajar siswa. Namun, peneliti menetapkan dua model pembelajaran yang akan diuji, yaitu model pembelajaran Problem Based Learning (PBL) dan model pembelajaran Direct Instruction.

SMK Negeri 1 Kabupaten Tulungagung merupakan sekolah yang banyak memperoleh prestasi terutama yang diperoleh oleh siswa-siswa jurusan Teknik Komputer dan Jaringan. Juara 1 Lomba Karya Siswa tingkat Kabupaten Tulungagung tahun 2016 dan menjadi wakil dari Kabupaten Tulungagung di tingkat Jawa Timur. Berdasarkan observasi dan wawancara tidak terstruktur yang telah dilakukan sebelumnya oleh peneliti kepada wakil kepala sekolah bagian kurikulum, didapatkan temuan bahwa setiap lulusan dari SMK 1 Boyolangu selalu memenuhi target kriteria umum lulusan Sekolah Menengah Kejuruan. 


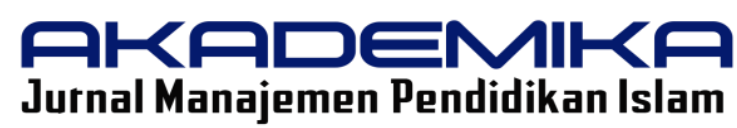

INSTITUT AGAMA ISLAM SUNAN KALIJOGO MALANG

P-ISSN 2622-9293 / E-ISSN 2721-9658

Volume 3 Nomor 1 Juni 2021

Penelitian ini akan mendiskripsikan berapa banyak guru yang menerapkan model pembelajaran Problem Based Learning atau yang menerapkan model pembelajaran Direct Instruction, serta model pembelajaran yang paling tinggi tingkat penggunaannya di mata pelajaran produktif kelas X jurusan Teknik Komputer dan Jaringan (TKJ) di SMK Negeri 1 Boyolangu.

\section{KAJIAN TEORI}

Model pembelajaran adalah pola yang digunakan sebagai pedoman dalam merancang pembelajaran di kelompok maupun tutorial (Suprijono, 2012:46). Fungsi model pembelajaran menurut Trianto (2011:51) adalah sebagai pedoman bagi perancang dan para guru dalam melaksanakan pembelajaran. Model pembelajaran merupakan pedoman bagi perancang dan para guru dalam melaksanakan pembelajaran, memberikan arah dalam pendesainan pembelajaran dalam rangka membantu peserta didik mencapai berbagai tujuan dan/atau kompetensi.

Model pembelajaran Problem Based Learning atau Pembelajaran Berbasis Masalah (PBL) dikembangkan berdasarkan konsep-konsep yang dicetuskan oleh Jerome Brunce. Pembelajaran Problem Based Learning adalah pendekatan yang efektif untuk pengajaran proses berpikir tinggi, Rutmanan (dalam Trianto, 2011:68). Ditekankan lagi oleh Ibrahim dan Nur (dalam Trianto, 2011:65) model pembelajaran Problem Based Learning bertujuan untuk membentuk siswa mengembangkan kemampuan berfikir, memecahkan masalah dan ketrampilan intelektual belajar tentang berbagai peran orang dewasa memalui perbuatan mereka, dalam pengalaman yang nyata atau simulasi, dan menjadi siswa yang otonom dan mandiri.

Tabel 2.1 Fase-Fase Model Problem Based Learning

\begin{tabular}{ll}
\hline Fase-Fase & Perilaku Guru \\
\hline Fase 1: Memberikan orientasi tentang & Guru menyampaikan tujuan \\
permasalahannya kepada peserta & pembelajaran, mendiskripsikan \\
didik & berbagai kebutuhan logistik penting \\
& dan memotivasi peserta didik untuk \\
& terlibat dalam kegiatan mengatasi \\
& masalah
\end{tabular}


Fase 2: Mengorganisasikan peserta didik untuk meneliti

Fase 3: Membantu investigasi mandiri dan kelompok

Fase 4: Mengembangkan dan mempresentasikan artifak dan exhibit

Fase 5: Menganalisis dan mengevalusi proses mengatasi masalah
Guru membantu peserta didik mendefinisikan tugas-tugas belajar terkait dengan permasalahanya Guru mendorong peserta didik untuk mendapatkan informasi yang tepat, melaksanakan eksperimen, dan mencari penjelasan dan solusi Guru membantu peserta didik dalam merencanakan dan menyiapkan artifak-artifak yang tepat, seperti laporan, rekaman video, dan modelmodel, serta membantu mereka untuk menyampaikan kepada orang lain

Guru membantu peserta didik melakukan refleksi terhadap investigasinya dan proses-proses yang mereka lakukan.

\section{(Sumber: Ibrahim dan Nur (dalam Trianto, 2011:71-72))}

Model pembelajaran Direct Instruction atau pembelajaran langsung, menurut Arend yang dikutip Trianto (2011:29) adalah salah satu pendekatan mengajar yang dirancang khusus untuk menunjang proses belajar siswa yang berkaitan dengan pengetahuan deklaratif dan pengetahuan prosedural yang terstruktur baik yang dapat diajarkan dengan pola kegiatan yang bertahap, selangkah demi selangkah. Kardi (dalam Trianto, 2011:30) pembelajaran Direct Instruction dapat berbentuk ceramah, demonstrasi, pelatihan atau praktik dan kerja kelompok. Pengajaran langsung digunakan untuk menyampaikan pelajaran yang ditransformasikan langsung oleh guru kepada siswa. Model pembelajaran Direct Instruction merupakan salah satu pendekatan mengajar yang dirancang khusus untuk menunjang proses belajar siswa, yang mana gaya mengajar yang diterapkan mengacu pada keterlibatan guru dalam mengusung isi pembelajaran kepada peserta didik dan mengajarkannya secara langsung kepada seluruh kelas. 
Tabel 2.2 Fase-Fase Model Pembelajaran Direct Instruction

\begin{tabular}{ll}
\hline Fase-Fase & Perilaku Guru \\
\hline Fase 1: Menyampaikan tujuan dan & Guru menjelaskan tujuan \\
mempersiapkan siswa & $\begin{array}{l}\text { pembelajaran, informasi latar } \\
\text { belakang pelajaran, mempersiapkan } \\
\text { siswa untuk belajar }\end{array}$ \\
& Guru mendemonstrasikan \\
Fase 2: Mendemonstrasikan & ketrampilan dengan benar atau \\
pengetahuan dan ketrampilan & menyajikan informasi tahap demi \\
& tahap \\
& Guru merencanakan dan memberi \\
Fase 3: Membimbing pelatihan & pelatihan awal \\
Fase 4: Mengecek pemahaman dan & Guru mengecek apakah siswa telah \\
memberi koreksi & berhasil melakukan tugas degan baik, \\
& memberi koreksi \\
Fase 5: Memberikan kesempatan & Guru mempersiapkan kesepatan \\
untuk pelatihan dan penerapan & melakukan penelitian lanjutan, \\
& dengan perhatian khusus pada \\
& penerapan kepada situasi lebih \\
& kompleks dan kehidupan sehari-hari \\
&
\end{tabular}

(Sumber: Ibrahim dan Nur (dalam Trianto, 2011:71-72))

\section{METODE PENELITIAN}

Penelitian ini menggunakan pendekatan diskriptif kualitatif dengan jenis penelitian penelitian lapangan (Field Research). Jenis penelitian yang digunakan adalah penelitian lapangan (Field Research). Field Research merupakan pengamatan tentang sesuatu fenomena dalam suatu keadaan alamiah atau 'in situ', sehingga peneliti terjun langsung ke lapangan (Sugiyanto, 2008:321). Field Research dipilih karena peneliti mengadakan penelitian untuk meneliti berapa banyak guru yang menerapkan model pembelajaran Problem Based Learning atau model pembelajaran Direct Instruction serta model pembelajaran yang paling tinggi tingkat penggunaannya di mata pelajaran produktif kelas X jurusan Teknik Komputer dan Jaringan (TKJ) di SMK Negeri 1 Boyolangu. 


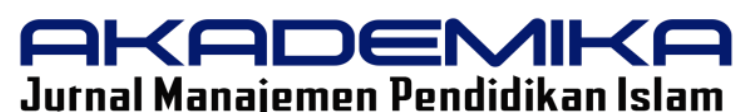

INSTITUT AGAMA ISLAM SUNAN KALIJOGO MALANG

P-ISSN 2622-9293 / E-ISSN 2721-9658

Volume 3 Nomor 1 Juni 2021

Instrumen atau alat penelitian dalam penelitian kualitatif adalah peneliti itu sendiri (human instrument), Sumber data primer penelitian ini adalah guru kelas kelas X mata pelajaran Produktif jurusan Teknik Komputer dan Jaringan SMK Negeri 1 Boyolangu. Guru diambil sebagai sumber data primer dalam penelitian ini dikarenakan guru merupakan pelaksana utama dalam pelaksanaan model pembelajaran di kegiatan belajar mengajar. Sementara, data sekunder yang digunakan adalah Silabus dan RPP. Teknik pengumpulan data yang digunakan dalam penelitian ini adalah observasi partisipasi pasif, wawancara terstruktur dan dokumentasi.

Teknik analisis data dan pengolahan data dilakukan dalam beberapa tahapan. Tahap pertama, pengolahan data dimulai dari penelitian pendahuluan hingga tersusunnya usulan penelitian. Tahap kedua, pengolahan data lebih mendalam dilakukan dengan cara mengolah hasil kegiatan wawancara dan pengumpulan berbagai informasi lapangan di lokasi penelitian. Tahap ketiga, setelah itu dilakukan pemeriksaan keabsahan data hasil wawancara dengan sejumlah narasumber yang dijadikan informan penelitian serta membandingkan data tersebut dengan berbagai informasi yang terkait. Pengecekan keabsahan temuan pada penelitian ini menggunakan teori dari Sugiyono. Pengecekan keabsahan temuan penelitian ini meliputi uji credibility, uji transferability, uji dependability, dan uji comfirmability.

\section{HASIL DAN PEMBAHASAN}

Berdasarkan pembahasan semua informan dari hasil wawancara, hasil observasi kelas dan angket siswa yang dilakukan di SMK Negeri 1 Boyolangu ditemukan hasil sebagai berikut:

- Guru yang menerapkan model pembelajaran Problem Based Learning (PBL) di mata pelajaran produktif kelas X jurusan Teknik Komputer dan Jaringan (TKJ) sebanyak 4 orang yaitu Informan 1, Informan 2, Informan 4 dan Informan 5.

- Guru yang menerapkan model pembelajaran Direct Instruction (DI) di mata pelajaran produktif kelas X jurusan Teknik Komputer dan Jaringan (TKJ) sebanyak 1 orang guru yaitu Informan 3.

- Model pembelajaran yang paling tinggi tingkat penggunaannya adalah model pembelajaran Problem Based Learning (PBL).

Garis besar penelitian ini adalah tentang model pembelajaran yang difokuskan pada model pembelajaran Problem Based Learning (PBL) dan Direct Instruction (DI). Menurut kawasan Teknologi Pendidikan, model pembelajaran termasuk dalam kawasan desain strategi 


\section{GRPDENIKP \\ Jurnal Manajemen Pendidikan Islam}

INSTITUT AGAMA ISLAM SUNAN KALIJOGO MALANG

P-ISSN 2622-9293 / E-ISSN 2721-9658

Volume 3 Nomor 1 Juni 2021

pembelajaran. Hal ini sesuai dengan Seels (1994:34) yang menyatakan strategi pembelajaran berinteraksi dengan situasi belajar, situasi-situasi belajar sering dinyatakan dalam modelmodel pembelajaran, model pembelajaran maupun strategi pembelajaran yang diperlukan untuk mengaplikasikannya berbeda-beda tergantung pada situasi belajar, sifat materi dan jenis belajar yang diinginkan.

Penelitian ini menghasilkan data empat orang informan guru yang menggunakan model pembelajaran Problem Based Learning (PBL) dan satu orang informan guru yang menggunakan Direct Instruction (DI). Menurut aliran-aliran pemikiran pada kawasan desain Tekonologi Pendidikan (Seels, 1994:79), guru yang menggunakan model pembelajaran Problem Based Learning (PBL) maupun Direct Instruction (DI) termasuk dalam aliran Teknologi Pendidikan dan Penelitian Belajar-Mengajar.

\section{KESIMPULAN}

Kesimpulan dari penelitian yang bertujuan untuk meneliti berapa banyak guru yang menerapkan model pembelajaran Problem Based Learning dan guru yang menerapkan model pembelajaran Direct Instruction serta model pembelajaran yang paling tinggi tingkat penggunaannya di mata pelajaran produktif kelas X jurusan Teknik Komputer dan Jaringan (TKJ) di SMK Negeri 1 Boyolangu, adalah sebagai berikut:

- Model pembelajaran Problem Based Learning (PBL) diterapkan oleh 4 orang guru yaitu Informan 1, Informan 2, Informan 4 dan Informan 5.

- Model pembelajaran Direct Instruction (DI) diterapkan oleh 1 orang guru yaitu Informan 3.

- Model pembelajaran yang paling tinggi tingkat penggunaannya adalah Problem Based Learning. 


\section{คКคDEMIKค \\ Jurnal Manajemen Pendidikan Islam}

INSTITUT AGAMA ISLAM SUNAN KALIJOGO MALANG

P-ISSN 2622-9293 / E-ISSN 2721-9658

Volume 3 Nomor 1 Juni 2021

\section{DAFTAR PUSTAKA}

Agustianto, Kafidurrohman. 2014. Studi Pelakasanaan Model Pembelajaran pada Mata Pelajaran Produktif Kelas X SMK Negeri di Kabupaten Ponorogo. Skripsi tidak diterbitkan. Malang: Universitas Negeri Malang

Seels, B Barbara dan Richey C Rita. 1994. Teknologi Pendidikan: Definisi dan Kawasannya. Jakarta: Unit Percetakan Universitas Negeri Jakarta

Sinaga, Nelson \& Nasution, Haris. 2013. Pengaruh Strategi Pembelajaran Problem Based Learning (PBL) terhadap Hasil Belajar Merakit Personal Computer (PC) pada Siswa Kelas X Teknik Komputer dan Jaringan di SMK Negeri 1 Tanjung Pura. (Online). (http://digilib.unimed.ac.id), diakses 12 februari 2019.

Sugiyono. 2008. Metode Penelitian Pendidikan: Pendekatan Kuantitaif, Kualitatif, R\&D. Bandung: Alfabeta.

Suprijono, Agus. 2012. Cooperative Learning: Teori dan Aplikasi PAIKEM. Yogyakarta: Pustaka Belajar.

Toha, Habib dkk. 2014. Penerapan Model Pembelajaran Berbasis Masalah untuk Meningkatkan Hasil Belajar Siswa TKJ pada Pelajaran Jaringan Dasar, 3. (Online), (http://ejournal.undhiksha.ac.id), diakses 4 Februari 2019.

Trianto. 2011. Model-Model Pembelajaran Inovatif Berorientasi Konstruktivistik. Jakarta: Prestasi Pustaka Publisher.

Trianto. 2011. Model Pembelajaran Terpadu dalam Teori dan Praktik. Jakarta: Prestasi Pustaka Publisher. 